\title{
On the Food and Feeding Habits of Lepidomysis longipes (Pillai \& Mariamma) (Crustacea Mysidacea)
}

\author{
C.N. NATH $*$ and N.K. PILLAI **
}

Lepidomysis longipes is a subterranean mysid inhabiting the freshwater wells at Kottayam, Kerala, S. India. The wells are rather deep pits excavated to obtain regular supplies of drinking water. As such, they are protected by a circular embankment about a meter high from the ground level. This embankment prevents the entry of extraneous matter into the well. Therefore, the well water is practically devoid of food materials for the mysids. This apparent paucity of food in the habitat prompted us to make a detailed study of the food and feeding habits of the animal.

\section{H A B I T A T}

A short description of these wells is necessary here. The well from which $L$. longipes were collected for study is an open pit, about $12 \mathrm{~m}$ deep. The maximum depth of the water column in the well during the monsoons is about $3 \mathrm{~m}$, while the minimum during summer is $1 \frac{1}{2} \mathrm{~m}$. During the last fifty years, there is no record of the water in the well having completely dried up. The well is emptied annually for cleaning purposes, but water flowing in through the subterranean springs fills up the well in a short time. These underground springs thus provide a perennial supply of water which is always clear and devoid of suspended particles.

The well has a thin layer of bottom deposit of fine mud mixed with decaying organic matter. The sediment layer is generally 7 to $15 \mathrm{~cm}$ thick. The upper parts of the side walls of the well from the ground level to a depth of 1 to $1.3 \mathrm{~m}$ always show a profuse growth of vegetation composed of ferns, mosses and a few flowering plants. The dead leaves from these fall into the water below, undergo decay and add to the organic content of the sediment. Even in wells cleaned annually, there is generally a growth of these plants providing organic substance to the bottom sediment. The water also harbours algal forms like Spirogyra, Mucor and Oscillatoria.

During summer, every year, when the level of the water is low, the wells at Kottayam are emptied and thoroughly cleaned. The cleaning operations are so thorough that all the animals and vegetable matter in the well is completely removed. Yet within a few days the mysids reappear in the well, indicating that they gain entry into the wells through the underground channels.

* Dept. of Zoology, Govt. P.G. College, Mandsaur, M.P.

** Marine Biology Laboratory, Trivandrum-7, S. India. 


\section{E T H O D S}

The mysids were collected by the following procedure. A bucket full of water is drawn in and out of the water column to ensure thorough mixing of the bottom sediment with the water. This is necessary because the mysids almost always remain close to the bottom. A known quantity of the water is then drawn out with the contained detrital matter and animals. Mysids were taken out for study. The rest of the water is filtered through a fine-meshed cloth. Random samples of the filtrate are analysed quantitatively to determine the nutrient material. With the volume of the sample of filtrate and the water known, the quantity of nutrients in a cubic metre of the water was calculated. It is not suggested that the calculation is accurate. However, it gives an approximate idea of the amount of nutrients available in the medium.

A quantitative analysis of the bottom sample shows the following ingredients in one cubic metre of water. This is a modification of the method employed by Ross (1906).

\section{Vegetable matter}

Fragments mostly of phanerogamous origin and about $1000 \mu$ long

$2,840,000$

Fragments mostly of ferns \& mosses above $500 \mu$ and below $1000 \mu$

$3,230,000$

Fragments below $500 \mu$.

Algal filaments and fragments .

$41,850,000$

30,000

Spore cases

20,000

Total vegetable matter .

$47,970,000$

\section{Animal matter}

Protozoans, mainly vorticellids and other ciliates

Rotifers .

Cyclopoid copepods

Harpacticoid copepods

Total organic matter

The minute vegetable particles were not taken into account because of the difficulty in sorting them. One cubic metre of water contained $238.45 \mathrm{cc}$ of detritus. Of these, nearly $209.84 \mathrm{cc}$ were mainly mud and this forms $88 \%$ of the total mass. This would mean that only $12 \%$ of the detrital matter $(28.16 \mathrm{cc} / \mathrm{cubic}$ metre) was organic in nature capable of constituting food material in the medium. This, however, is a very conservative estimate, since fine particles were left out.

It has to be remembered that the estimate given above pertains only to the organic matter available in the well bottom. We have no idea about the amount of food available, if any, to the animals in the subterranean channels.

Examination of the stomach of 120 mysids revealed large quantities of mud in it. In addition, there were considerable amounts of vegetable matter and broken 
piece of the exoskeletal parts of arthropods. The vegetable matter was constituted chiefly of decayed leaves, very small algal filaments etc.

\section{F E E D I N G H A B I T S}

L. longipes is almost unique among mysids because of its discontinuous feeding. Subterranean life has brought about very interesting modifications in its feeding habits.

Due to the difficulty in keeping L. longipes alive in the laboratory for long periods, it was not possible to make lengthy observations. When they were reared in water from the original habitat and kept in earthen pots with a layer of the sediment from the well bottom, they survived for a maximum of two weeks.

Examination of the animals in the early hours of the morning revealed that the stomach is invariably full and the rest of the alimentary canal nearly empty or with some food matter in the posterior half of the midgut. Significantly enough, the entire alimentary canal has never been found to be filled with food, unlike as in the epigean mysids examined. Even when they were left in a container with enough food, complete filling of the gut was never observed.

During the present study, it was observed that the food is retained in the stomach for nearly four hours. The rest of the alimentary canal is traversed by the food in eight hours and thirty minutes. Benko (1962) working on the Russian mysids found that "the gut becomes totally empty after $3 \frac{1}{2} \mathrm{hrs}$ to $4 \mathrm{hrs}$ after intake of food, if there is no flow of new food". Therefore, the long time taken by $L$. longipes to empty the gut appears peculiar.

The index of filling of the gut calculated on the basis of the ratio of the weight of the food consumed and the weight of the organism, (Benko, 1962) is bound to be very small in Lepidomysis. So is the index of daily consumption, which is equal to the index of filling of the gut multiplied by 24 and divided by the time taken for digestion.

Thus, if ' $x$ ' is the weight of the body of the animal and ' $y$ ' that of the food consumed, the index of filling ' $\mathrm{f}$ ' can be expressed as, $f=\frac{y}{x}$

Similarly, if ' $t$ ' is the time taken for the digestion of the food, the index of daily consumption ' $d$ ' can be expressed thus, $d=\frac{f \times 24}{t}$

where 24 represents the hours in a day. Evidently, the value for 'd' will be much smaller for L. longipes, which digests food in 12 to $13 \mathrm{hrs}$., than in the epigean mysids studied by Benko, which take a maximum of $3 \frac{1}{2}$ to 4 hrs for digestion.

Though on occasion a dead juvenile specimen was seen to be eaten by an adult female, L. longipes does not appear to be cannibalistic as Hemimysis lamornae (Cannon \& Manton, 1926) or Neomysis vulgaris (Lucas, 1936). No other individual was found to fight for the booty. 


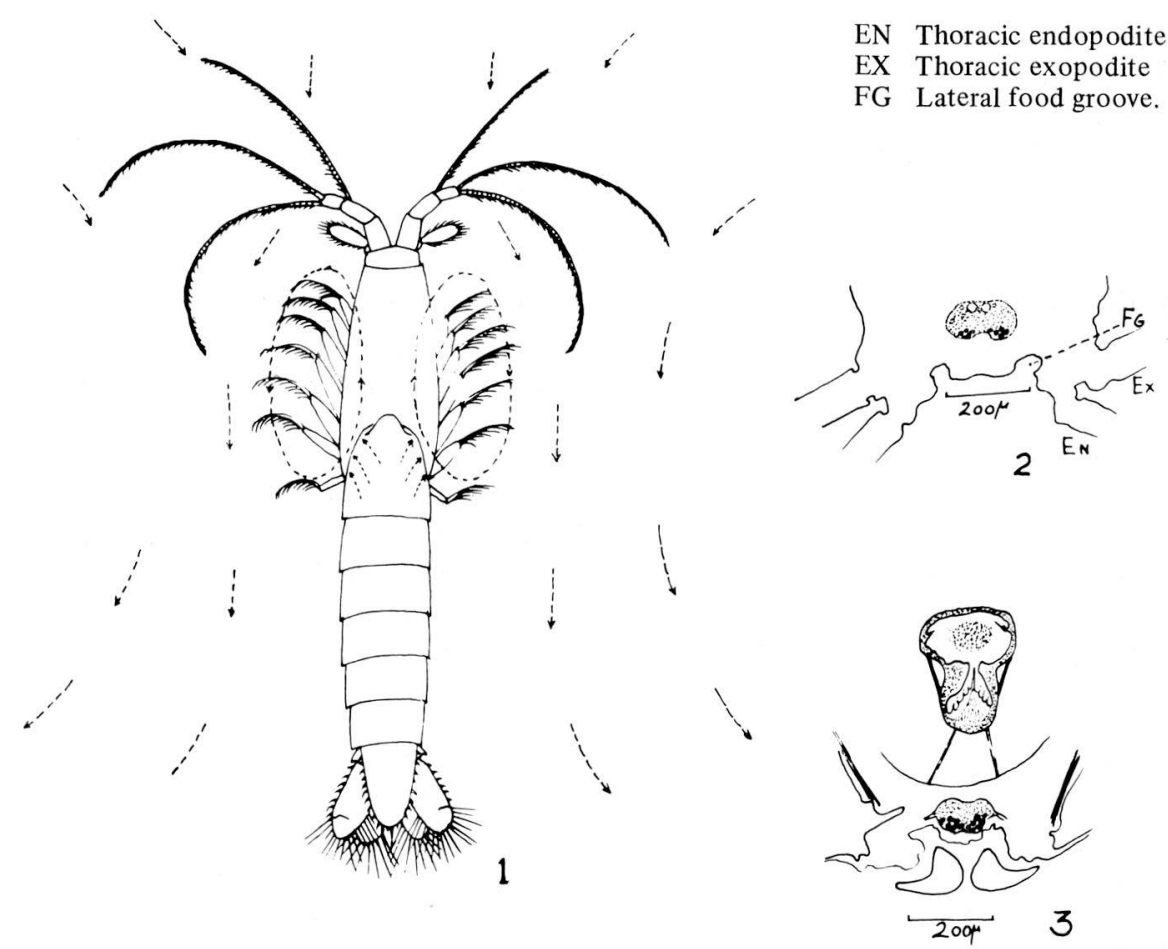

Fig. 1 Diagram to illustrate the movement of the thoracic Exopods and the feeding currents. The small arrows behind the carapace denote the current passing below the carapace.

Fig. 2. T.S. of body to show the ventrolateral food grooves and Sternal convexity.

Fig. 3. T.S. of the body to show the food basin near the maxillules.

Once the stomach is full, an individual stops feeding. Even if food is offered, it shows no interest in it. This is in contrast to the habit of the epigean mysids, which, provided the medium contains a high concentration of food, resorts to continuous feeding. Such continuous feeding is characteristic of many typical planktonic crustaceans.

The method of feeding of $L$. longipes differs from that described for $H$. lamornae by Cannon and Manton (1926). This modification seems to be the result of two factors.

a) The body of Lepidomysis is dorsoventrally flattened and this flattening makes the ventral groove rather shallow. The lateral shifting of the attachment of the thoracic appendages as a result of the flattening has made the groove wide. The convex median sternal wall divides the ventral food channel into two lateral channels 
b) The underground channels provide only very limited opportunity for active swimming and hence Lepidomysis only rarely moves fast. Consequently, a feeding current, even if it is produced, is feeble and intermittent.

The movements of the maxillary exites produce, by their quick back and forth motion, a suction pump action drawing water forwards through the lateral food channel mentioned above. Anteriorly, they meet the food basin at the level of the maxillules as in other mysids.

The axial food currents enter the food channel at the bases of the thoracic appendages. These currents are produced almost in the same way as in Hemimysis. But the elliptical movement of the thoracic expodites is dorsal and not lateral in Lepidomysis. This difference is also the result of the dorsoventral flattening of the body and the slight shifting of the attachment of the thoracic appendages.

In an attempt to find out whether there is any other method of feeding in the animal, a few individuals were left in a glass vessel containing water and supporting a growth of algal filaments. Previously starved invididuals immediately began to crawl over the sides of the vessel scraping off the algal filaments. The stomach of these animals, examined later, was found to contain these algal filaments. It is clear that, like many other mysids, $L$. longipes resorts to two different methods of feeding.

Though L. longipes exhibits both the maxillary suction pump part and the thoracic exopodite part of the filter feeding mechanism described by Cannon \& Manton (1926), it should be pointed out that these two feeding currents play only a subsidiary role in the feeding of the animal. It feeds mainly on large bits of food holding them between the maxillipeds. This is evident from the fact that unlike $H$. larmornae, L. longipes has never been observed to increase the quantity of suspended matter in the water by fanning close to the bottom with the thoracic exopods. They are generally found to swim close to the bottom without disturbing the sediment or slowly walking over it.

\section{O N C L US I O N}

Being subterranean, Lepidomysis has undergone some structural modifications. These modifications as well as the dearth of food has resulted in some remarkable changes in its feeding habits.

The animal feeds mainly on large particles of detrital matter and uses its maxillipeds, maxillae and mandibles to manipulate them. It also resorts to filter feeding at times. The latter method has only a subsidiary role in feeding.

$L$. longipes is a discontinuous feeder and the food takes a long time to pass through the alimentary canal. This appears to be correlated with the paucity of nutrients in the food. To extract the maximum out of the food, the animal keeps it in the alimentary canal for a very long time. As we have shown in an earlier paper (Nath \& Pillai, in press), the large number of secretory cells present in the hepatopancreas, not confined to glandular ridges and the digestive nature of the entire midgut seem to support this contention. 


\section{A C K N O W L E D G E M E N T}

Our thanks are due to Dr. N. Balakrishnan Nair, Professor, Marine Biology Laboratory, University of Kerala, Trivandrum-7, for providing necessary facilities for the present study.

\section{S U M M A R Y}

The amount of food available to the subterranean mysid, Lepidomysis longipes (Pillai \& Mariamma, 1964) in its habitat has been calculated and analysed. Lepidomysis appears to feed mainly on decaying vegetable matter.

Lepidomysis shows many modifications in its external morphology. Consequently, the mode of feeding has undergone some marked changes from that of its epigean relatives. $L$. longipes is a discontinuous feeder.

\section{R É S U M É}

La quantité de nourriture dont peut disposer dans son habitat le Mysidacé hypogé Lepidomysis longipes (Pillai et Mariamma, 1964) a été évaluée et analysée. Il en résulte que Lepidomysis se nourrit principalement de débris végétaux en décomposition.

Lepidomysis longipes montre de nombreuses modifications dans sa morphologie externe et de ce fait, le mode de nutrition subit quelques changements remarquables par rapport à celui des formes épigées, il est à noter qu'il a une alimentation du type discontinue.

\section{I T E R A T U R E}

BENKO, I. 1962. Some quantitative study of the food of mysids. Trud. Karadag. Sta; 18; pp. 37-43 (In Russian).

CANNON, H.G. and MANTON, S.M. 1926. On the feeding mechanism of a mysid Crustacean, Hemimysis lamornae. Trans. Roy. Soc. Edinburgh. 55, pt.1, no. 10, pp. 219-253, $4 \mathrm{pls}, 16$ text figs.

LUCAS, C.E. 1936. On certain interrelations between phytoplankton and Zooplankton, under experimental conditions. J. cons. int. Expl. Mer. 11 no.,3, pp. 343-361, 8 tabs.

NATH, C.N. \& PILLAI, N.K., 1971, Studies on the genus Lepidomysis Clarke. Crustacea: Mysidacea. Hydrobiologia, 37, 2, pp. 285-300.

NATH, C.N. and PILLAI, N.K., 1971, (in press) Studies on the alimentary canal of Spelaeomysis longipes (Pillai \& Mariamma). J. Zool. Soc. India.

ROSS, I., 1906, Food of Subterranean crustacea. Des Moines Proc. Iowa Acad. Sci., 13, pp. 273-276. 